\title{
Modulation of the heat shock response is associated with acclimation to novel temperatures but not adaptation to climatic variation in the ants Aphaenogaster picea and $A$. rudis
}

$31{ }^{a}$ Department of Biology, University of Vermont, Burlington, VT 05405 USA

${ }^{b}$ Department of Applied Ecology and Keck Center for Behavioral Biology, North

Carolina State University, Raleigh, NC 27695 USA

${ }^{\mathrm{c}}$ Department of Entomology, Smithsonian Institution, Washington DC 20013 USA.

Sara Helms Cahan ${ }^{\mathrm{a}}$, Andrew D. Nguyen ${ }^{\mathrm{a}}$, John Stanton-Geddes ${ }^{\mathrm{a}}$, Clint A. Penick ${ }^{\mathrm{b}}$, Yainna Hernáiz-Hernández ${ }^{\mathrm{a}}$, Bernice B. DeMarco ${ }^{\mathrm{c}}$, Nicholas J. Gotelli ${ }^{\mathrm{a}}$ 
42 Ecological diversification into thermally divergent habitats can push species

43 toward their physiological limits, requiring them to accommodate temperature extremes

44 through plastic or evolutionary changes that increase persistence under the local thermal

45 regime. One way to withstand thermal stress is to increase production of heat shock

46 proteins, either by maintaining higher baseline abundance within cells or by increasing

47 the magnitude of induction in response to heat stress. We evaluated whether

48 environmental variation was associated with expression of three heat shock protein genes

49 in two closely-related species of woodland ant, Aphaenogaster picea and A. rudis. We

50 compared adult workers from colonies collected from 25 sites across their geographic

51 ranges. Colonies were maintained at two different laboratory temperatures, and tested for

52 the independent effects of environment, phylogeny, and acclimation temperature on

53 baseline and heat-induced gene expression. The annual maximum temperature at each

54 collection site (Tmax) was not a significant predictor of either baseline expression or

55 magnitude of induction of any of the heat shock protein genes tested. A phylogenetic

56 effect was detected only for basal expression of $H s p 40$, which was lower in the most

57 southern populations of $A$. rudis and higher in a mid-range population of possible hybrid

58 ancestry. In contrast, a higher acclimation temperature significantly increased baseline

59 expression of $H s c 70-4$, and increased induction of $H s p 40$ and $H s p 83$. Thus,

60 physiological acclimation to temperature variation appears to involve modulation of the

61 heat shock response, whereas other mechanisms are likely to be responsible for

62 evolutionary shifts in thermal performance associated with large-scale climate gradients. 
63 Key Words: Heat shock proteins, Ants, Heat Shock Response, Hsc70-4, Hsp70, Hsp90,

64 Hsp40

65

66 Abbreviations:

67 Hsp, heat shock protein

$68 H s p$, heat shock protein gene

69 CSR, cellular stress response

70 Tmax, annual maximal temperature at the site of collection (Bioclim variable 5)

71 
72 Introduction

73

74 Temperature is a primary determinant of the geographic distributions of species

75 and an important selective force shaping organismal phenotypes (Cahill et al., 2014;

76 Diamond et al., 2012; Sunday et al., 2012). For small-bodied ectotherms such as insects,

77 whose body temperatures track external temperatures, maintaining a suitable internal

78 temperature can be challenging in the face of environmental variation (Stevenson 1985).

79 Excessively high temperatures can lead to protein denaturation, loss of membrane

80 integrity, neuronal failure, and death (White et al., 2007). To cope with such stressors,

81 organisms can behaviorally avoid thermal extremes or deploy a number of physiological

82 response mechanisms that prevent or repair heat-related damage (Feder and Hoffmann,

83 1999). One of the oldest and most conserved is the Cellular Stress Response (CSR), an

84 inducible reaction to perturbation and cellular damage characterized by production of

85 heat shock proteins (Hsps) — chaperone molecules that protect other proteins from

86 damage, refold those that have denatured, and help to dispose of irreversibly damaged

87 proteins (Lindquist, 1986; Parsell and Lindquist, 1993).

88 Because stress response mechanisms such as the CSR are structurally and

89 metabolically costly (Fitzgerald-Dehoog et al., 2012; Hoekstra and Montooth, 2013), the

90 extent to which they are employed is expected to track the risk of exposure to

91 temperature extremes. Individuals may respond plastically to changes in temperature

92 over time, enhancing Hsp production when acclimated to conditions in which they are

93 more likely to encounter stress (Fader et al., 1994; Hu et al., 2014). When thermal

94 regimes vary across space, such as along latitudinal or altitudinal gradients, divergent 
95 selection pressures acting on populations at different locations may promote evolutionary

96 changes instead of or in addition to an acclimation response (Addo-Bediako et al., 2000;

97 Sheth and Angert, 2014). In more extreme environments, populations are likely to

98 frequently face conditions at or beyond their physiological limits, selecting for increased

99 constitutive expression or enhanced inducibility of chaperone molecules (Barshis et al.,

100 2013; Bettencourt and Feder, 2001). Under milder conditions, however, the cost of

101 maintaining a response mechanism may lead to reduction or loss of the capacity to

102 respond to temperature extremes (Silbermann and Tatar, 2000). Moreover, if increasing

103 cold-tolerance comes at the expense of heat-tolerance (Rodriguez-Verdugo et al., 2014),

104 the entire thermal niche may be forced downward as populations approach their lower

105 thermal range limit (Addo-Bediako et al., 2000; Anderson et al., 2003).

106 Determining whether variation in thermal physiology is plastic or evolved is critical

107 for estimating the thermal safety margin of populations facing future changes in climate

108 (Sawall et al., 2015). If physiological coping mechanisms have been evolutionarily lost at

109 the local level, populations may have significantly lower resilience than that suggested by

110 the thermal range across which the species as a whole occurs (Martinez et al., 2015; Rojo

111 et al., 2015). Yet most studies of natural systems investigating evolutionary adaptation of

112 the CSR have compared only a small number of populations or species from discrete

113 habitat types (e.g., Koenigstein et al., 2013; Palumbi et al., 2014; Tedeschi et al., 2016).

114 Variation in Hsp expression patterns across continuous gradients in temperature have

115 been less frequently investigated (Mizrahi et al., 2015; Schoville et al., 2012).

116 The ant genus Aphaenogaster is common in deciduous forests in eastern North

117 America (Lubertazzi, 2012). The eastern clade of this genus, which includes 13 
118 morphologically delimited species, underwent a recent radiation within the last 5my

119 associated with post-glacial range expansion (Demarco and Cognato, 2016). Despite

120 their recent genetic divergence, however, species of Aphaenogaster occupy a wide range

121 of thermal environments, with mean annual temperature varying from 5 to $22^{\circ} \mathrm{C}$.

122 Environmental temperature is correlated with species occurrence at regional

123 biogeographic scales and along local elevational gradients (Warren and Chick, 2013).

124 Evidence from the warm-edge boundary of the geographic range of $A$. rudis suggests that

125 it is sensitive to upper thermal extremes: in a controlled field experiment, the incidence of

126 A. rudis declined in heated environmental chambers (Pelini et al., 2014, Diamond et al.,

127 2016).

128 In this study, we compared the expression patterns of heat shock proteins in two

129 widespread species of Aphaenogaster, the cool-climate A. picea and the warm-climate A.

130 rudis, whose geographic ranges overlap broadly in the southern and central Appalachian

131 Mountains of the eastern United States. We collected colonies of the two species from 25

132 sites along a latitudinal transect, spanning an $8.3^{\circ} \mathrm{C}$ gradient in maximal annual

133 temperature (Table S1). To evaluate the acclimation response in addition to

134 population/species-level evolutionary divergence in the CSR, we maintained colonies

135 from these sites at two different common-garden rearing temperatures. Workers were

136 assessed for baseline Hsp expression and induction in response to static sublethal heat

137 shock for three stress-inducible heat shock protein genes whose expression patterns are

138 associated with variation in thermal tolerance in ants: $H s p 40, H s c 70-4 \mathrm{~h} 2$ (one of two

139 heat-inducible genes in the Hsp70 gene family in ants), and Hsp83 (Gehring and Wehner,

140 1995; Nguyen et al., 2016). 
142 Methods

144 Field collections and lab acclimation

145 Aphaenogaster colonies were collected in the summer of 2013 at 25 sites along

146 the eastern seaboard of the US (Fig. 1A; Table S1). Whole colonies were collected by

147 overturning rocks and breaking open downed twigs and logs to locate colonies, and

148 aspirating into a collection chamber the queen and as many individual adults and brood of

149 all life stages as could be collected in $\sim 5$ minutes. Voucher specimens were pinned for

150 each colony and identified to species by a single taxonomic expert (B. DeMarco).

151 Morphological criteria used to identify A. picea include a blackish-brown body, medium-

152 length spines (two-thirds of the length of the thoracic declivity) and lighter color of the

153 last four antennal segments. In contrast, $A$. rudis is characterized by a reddish-brown

154 body, short spines (less than half the length of the thoracic declivity) and uniformly

155 colored antennal segments. All taxonomic identifications were made without knowledge

156 of the collection locale.

157 One to four colonies per site were established between July 9 and July 29, 2013 in

158 common-garden laboratory conditions at North Carolina State University. All existing

159 eggs, larvae and pupae were removed from each colony to prevent mixing of field and

160 laboratory-reared individuals in gene-expression experiments, and the remaining adults

161 were housed in plastic nest boxes with a plaster floor in which two $16 \times 150 \mathrm{~mm}$ test

162 tubes partially filled with water that was plugged by a cotton ball were provided as brood

163 chambers. The plaster in each nest was moistened daily with distilled water to 
164 maintain humidity. We fed colonies an artificial diet designed specifically for ants

165 (Bhatkar and Whitcomb, 1970) that we changed 3 times per week and

166 supplemented with freeze-killed beetle larvae (Zophobas morio) and vials

167 containing $20 \%$ sucrose solution.

168 One to two replicate colonies from each site were assigned randomly to low

169 rearing-temperature $\left(20^{\circ} \mathrm{C}\right)$ and high rearing-temperature $\left(26^{\circ} \mathrm{C}\right)$ treatments; sites from

170 which only a single colony was available were assigned randomly to a single temperature

171 treatment. Thirty-three colonies were reared at $20^{\circ} \mathrm{C}$ and 24 colonies were reared at $26^{\circ}$

$172 \mathrm{C}$, for a total of 57 colonies. The lower of these temperatures represents a mid-point value

173 of the mid-summer nest temperatures likely to be encountered across the collection sites

174 based on field measurements $\left(17-23^{\circ} \mathrm{C}\right.$, C. Penick, unpublished field measurements);

175 both rearing temperatures are well below the threshold temperature at which any of Hsp

176 genes assayed is activated in response to acute heat stress in adult A. picea workers

177 (35 C; Nguyen et al., 2016).

178

179 Genotyping by double digested restriction site-associated DNA sequencing (ddRADseq)

180 To control for the effect of shared ancestry on phenotypic trait values, we

181 conducted SNP discovery and genotyping using double-digest RADseq (ddRADseq), and

182 used the resulting SNP genotypes to reconstruct genetic relationships among the

183 experimental colonies. Genomic DNA was extracted from tissue of a single worker from

184 each colony with the Qiagen DNAeasy kit according to the manufacturer's instructions.

185 Ant tissue was homogenized prior to extraction with $\sim 201.4 \mathrm{~mm}$ zirconium silicate beads

186 in 200ul chilled ATL buffer for three minutes in a Next Advance Bullet blender spinning 
187 at maximum speed. A single worker sample of A. fulva was also extracted as an

188 outgroup.

189 Samples were genotyped in pooled sets of 48 individually-barcoded ddRADseq

190 libraries constructed from 100-200ng of genomic DNA per individual following the

191 protocol of Recknagel et al. (2013). Briefly, samples were double-digested with the

192 restriction enzymes NlaIII and $\mathrm{MluCl}$ at $37^{\circ} \mathrm{C}$ for three hours, purified using a $1.5 \mathrm{X}$

193 concentration of AMPure purification beads (Beckman Coulter Life Sciences, USA), and

194 quantified with a Qubit analyzer. The purified samples were ligated to barcoded P1 and

195 universal P2 adaptors, and sample concentrations were normalized by pooling 40ng of

196 each sample into a single library. Three hundred microliters of the pooled library was

197 purified with a 1X AMPure bead purification eluted into 30ul of Qiagen AE buffer. The

198 ligated fragments were amplified in seven 20ul PCR reactions containing approximately

199 20ng of DNA with the PhusionTaq PCR kit. The appropriate number of PCR cycles was

200 determined empirically by comparing amplification intensities of 11, 13 and 15 cycles;

201 the final library was constructed using 13 cycles. The combined PCR reactions were

202 pooled and purified with 1.5X AMPure beads into a final volume of 30ul. Fragments

203 300-400bp in total length were size-selected from a 1.5\% agarose gel and extracted with

204 the QIEX II gel extraction kit. Library size range and quality were verified on a

205 Bioanalyzer and with kapa qPCR. Each library was single-end sequenced in a single

206 HiSeq 2000 rapid-run lane at the University of Vermont Advanced Genome

207 Technologies Core facility, yielding approximately 2.5 million reads per sample.

208 Sequences were demultiplexed using the program sabre

209 (https://github.com/najoshi/sabre), allowing for up to a single base pair mismatch in the 
210 barcoding sequence, and the restriction site sequence was trimmed. The total length of

211 all sequences was trimmed to 90bp with the fastx_trimmer tool in the FASTX Toolkit v.

2120.0 .14 , and low-quality reads, defined as those whose quality score dropped below 10 at

213 any point along the sequence, were excluded from downstream analysis with the

214 fastq_trimmer tool.

215 Because there is no sequenced genome available for the genus Aphaenogaster or

216 closely related ant genera, we used a reference set of five samples from across the

217 geographic extent of the transect to identify a repeatable subset of loci exhibiting

218 Mendelian genotypes, which was then used as a reference against which the complete

219 sample set was mapped and genotyped. The reference sample sequences were assembled

220 into homologous tags using the denovo.pl pipeline in STACKS. We retained those tags

221 for which a) there were from zero to three SNPs present across the five samples, b) all

222 five samples contained one or more reads at the tag, c) all SNPs were biallelic, and d) all

223 samples contained no more than two alternate haplotypes. The consensus sequences of

224 the 61,518 retained tags were assembled into a FASTA reference file, and the quality-

225 filtered sequence reads of all samples including the reference samples were mapped

226 against the reference with Bowtie. SNP genotypes were identified by assembling the

227 mapped reads into stacks using the ref_map.pl pipeline in STACKS with a minimum of

228 two reads to call a genotype. For each sample, the SNP genotypes across tags were

229 concatenated into a single pseudo-sequence that was used for all downstream

230 biogeographic analyses.

231

232 Heat shock treatment 
Workers from all colonies were subjected to static heat shock on September 3-4

234 2013, 5-8 weeks after establishment of field-collected colonies in common-garden

235 conditions. At this stage, the first cohort of laboratory-produced progeny had not yet

236 eclosed as adults, so all experimental animals had experienced at least some exposure to

237 field conditions as adults prior to common-garden acclimation.

238 For each colony, two groups of four workers were sampled haphazardly from the

239 colony. Each group was placed into a single $45 \mathrm{~mm}$ screw-cap glass vial and fully

240 submerged in either a baseline temperature $\left(25^{\circ} \mathrm{C}\right)$ or a sublethal heat shock $\left(37^{\circ} \mathrm{C}\right)$

241 circulating water bath treatment. After 1 hour, the ants were flash-frozen in liquid

242 nitrogen and stored at $-80{ }^{\circ} \mathrm{C}$ for gene expression quantification.

244 Quantifying Hsp gene expression

245 RNA was isolated from each set of four pooled ants using the RNeazy micro kit

246 (Qiagen, USA) following the manufacturer's instructions. 50ng of RNA was converted

247 to cDNA using the High Capacity cDNA reverse transcription kit (Life Technologies,

248 USA). We quantified gene expression using quantitative PCR for three heat shock protein

249 genes (Hsp83,Hsc70-4 h2, and Hsp40; Table 1) and one house-keeping gene (18s rRNA)

250 whose standard deviation in expression was confirmed to be below 2 (Dheda et al.,

251 2004), run in duplicates on an ABI StepOnePlus Real-Time PCR machine. Each reaction

252 was comprised of $2 \mathrm{ng}$ of template cDNA, $500 \mathrm{nM}$ of total primers, and $10 \mathrm{uL}$ of Power

253 SYBR® Green Master Mix (Life Technologies, USA), with a cycling program of heating

254 at $95^{\circ} \mathrm{C}$ for 10 minutes, and then 40 cycles of $95^{\circ} \mathrm{C}$ for 15 seconds, $60^{\circ} \mathrm{C}$ for 60 seconds, 
255 and acquisition of fluorescence at $70{ }^{\circ} \mathrm{C}$ for 60 seconds. We performed a melt-curve

256 analysis and sequenced a subset of samples to verify specificity.

257 Gene expression was quantified using the $\Delta \Delta \mathrm{CT}$ method (Livak and Schmittgen,

258 2001). For basal expression, we used the mean CT values across all samples for each Hsp

259 and housekeeping gene treated at $25^{\circ} \mathrm{C}$ as the reference to calculate relative quantity for

260 each sample. To quantify induction of each gene, we calculated fold-increase as the CT

261 values at $37^{\circ} \mathrm{C}$ relative to $\mathrm{CT}$ values at $25^{\circ} \mathrm{C}$ for each colony.

262

263 Statistical Analyses

264 We determined the effects of shared ancestry, thermal niche, and acclimation

265 temperature on baseline expression and fold-induction of each of the three heat shock

266 protein genes with linear regressions performed in R. Phylogenetic relationships were

267 estimated with RaxML 8 (Stamatakis, 2014) following a GTR+Gamma substitution

268 model; group support was evaluated with 100 fast bootstrap replicates. To convert

269 phylogenetic relationships into continuous variables suitable for a regression model, we

270 decomposed the phylogenetic distances with a principal coordinate analysis with the ape

271 statistical package (Paradis et al., 2004), which produces orthogonal eigenvectors that

272 capture different nodes across the tree (Fig. S1; Diniz et al., 1998). The first three

273 eigenvectors corresponded to the three deepest nodes with 100\% bootstrap support (Fig.

274 1); all three were included in the full models, but because Axis 1 was highly correlated

275 with Tmax (correlation coefficient $=0.836$ ), and therefore collinearity could have

276 prevented detection of an effect of environment, we also conducted the analyses without

277 Axis 1 . The results were identical, and only the full model results are presented here. 
278 Because the heat shock response is expected to impact fitness most strongly during

279 temperature extremes, we used annual thermal maximum (Tmax) at the collection site as

280 a proxy of field thermal conditions expected to impose selective pressure on expression

281 parameters. Substituting mean annual temperature (MAT) for Tmax produced identical

282 statistical results. Tmax values were extracted from the bioclim database

283 (http://www.worldclim.org/bioclim). To avoid over-fitting, we used forward selection of

284 variables based on AIC.

285

286 Results

287 A total of 80,847 SNPs from 42,655 unique tags were discovered across the set of

28857 ingroup colonies and the outgroup (A. fulva). As expected from morphological

289 identification, the majority of the ingroup colonies separated with $100 \%$ bootstrap

290 support into the two nominal species with overlapping geographic ranges: A. picea $(\mathrm{n}=42$

291 colonies), which was the predominant species at northern latitudes and extended as far

292 south as North Carolina at higher elevations, and A. rudis $(\mathrm{n}=12)$, whose range extended

293 from the southern edge of Pennsylvania to Georgia (Fig. 1). Two well-supported clades

294 within A. rudis associated with geography were evident in the SNP-based phylogenetic

295 reconstruction: the southern clade included all samples from the two southernmost sites

296 in Georgia and central North Carolina, whereas the northern clade encompassed the

297 remaining northern and western sites in Pennsylvania, North Carolina and Tennessee.

298 The southern clade included one sample from North Carolina (UN3) identified

299 morphologically as A. carolinensis. A third clade basal to both species was comprised of

300 two samples from site NK in central Pennsylvania as well as a single sample from site 
301 RW in upstate New York; two of these samples (NK 1 \& NK2) were morphologically

302 intermediate between A. picea and A. rudis, with the darker body color characteristic of

303 A. picea but lacking pale antennal tips. The third specimen (RW1) was identified as $A$.

304 picea. Principal Coordinate analysis produced three eigenvectors, representing $55.4 \%$ of

305 the total genetic variation, corresponding to the nodes splitting A. picea from A. rudis

306 (axis 1), the basal clade (axis 2), and the north-south split within A. rudis (axis 3; Fig.

307 1B).

308 All three heat shock protein genes ( $H s p 83, H s c 70-4$, and $H s p 40)$ were

309 successfully amplified by qPCR in all samples. Induction under heat shock varied

310 significantly among the three genes, with a 50.2-fold mean increase in expression of

$311 H s c 70-4$, while $H s p 83$ and $H s p 40$ were induced 11.2 and 10.5 -fold, respectively

312 (ANOVA; $F_{2,165}=102.3 ; \mathrm{p}<0.001$ ). Although the collection sites varied in Tmax from

$31325-33^{\circ} \mathrm{C}$, there was no relationship between Tmax and either basal expression or extent of

314 induction for any of the genes (Table 2, Fig. 2). Phylogeny was associated with Hsp

315 gene expression only for $H s p 40$, for which basal expression was significantly lower in the

316 southern clade of $A$. rudis than in all other clades, while the basal clade was significantly

317 higher overall but did not differ significantly from either A. picea or the northern clade of

318 A. rudis in post-hoc pairwise comparisons (Fig. 3).

319 Laboratory acclimation temperature, in contrast, had multiple significant effects

320 on gene expression patterns (Table 2). Basal expression of $H s c 70-4$ was significantly

321 higher when colonies were reared at $26^{\circ} \mathrm{C}$ than at $20^{\circ} \mathrm{C}$ (Linear regression, $\mathrm{t}_{55}=6.75, \mathrm{P}<$

322 0.001, Fig. 4C), and higher temperature increased the magnitude of induction in response

323 to heat shock in $H s p 40\left(\mathrm{t}_{53}=2.53, \mathrm{P}<0.05\right)$ and $H s p 83\left(\mathrm{t}_{55}=2.10, \mathrm{P}<0.05\right.$; Fig. $\left.4 \mathrm{~F}\right)$. 
325 Discussion

326 Aphaenogaster picea and A. rudis occupy broad but predominantly non-

327 overlapping thermal environments along the eastern seaboard of North America. In areas

328 of overlap, the two species differ by $2^{\circ} \mathrm{C}$ in critical thermal maxima and minima (Warren

329 and Chick, 2013), suggesting that selection on thermal limits may be driving evolutionary

330 divergence in the heat shock response. Despite this variation, however, we found little

331 evidence of evolved divergence in expression profiles of three heat shock proteins.

332 Instead, Hsp gene expression was phenotypically plastic: when reared at very warm

333 temperatures, both species increased baseline and induced expression of interacting genes

334 of the response pathway.

335 Comparative data from other taxa have shown an association between

336 environmental temperature and either higher constitutive expression of Hsp genes

337 (Bedulina et al., 2010; Li et al., 2014; Mizrahi et al., 2016; Shatilina et al., 2011) or a

338 stronger induced response (Chandrakanth et al., 2015; Dong and Williams, 2011;

339 Haguenauer et al., 2013; Li et al., 2014; Schoville et al., 2012; Shatilina et al., 2011;

340 Tedeschi et al., 2016; Yu et al., 2012). The comprehensive sampling in this study of

341 populations experiencing a wide range of Tmax values should have provided ample

342 power to detect a cline in gene expression if it were present, but Tmax was not related to

343 either constitutive or induced expression in any of the three Hsp genes (Fig. 2).

344 If A. picea and A. rudis have diverged in their upper thermal limits, why is this

345 not reflected in Hsp expression? It is possible that the difference is produced by aspects

346 of the heat shock response other than those measured in this study; response to heat stress 
347 and damage is a dynamic process, and the static heat shock treatment used here cannot

348 reveal variation in other important parameters such as temperature of activation, speed of

349 upregulation, or duration of maximal response, all of which are known to vary among

350 species as a function of thermal tolerance (Feder and Hofmann, 1999).

351 It is also possible that the heat shock response may not be the most important

352 factor conferring the specific type of thermal tolerance quantified in previous studies.

353 The Critical Thermal maximum (CTmax) can be measured in a number of different ways

354 that are often not strongly correlated with one another, suggesting different underlying

355 mechanisms (Blackburn et al., 2014; Terblanche et al., 2011). Previous comparisons

356 between Aphaenogaster species have used a rapid-heating protocol $\left(1^{\circ} \mathrm{C} \min ^{-1 ;}\right.$ Warren

357 and Chick, 2013); activation of the Hsp response requires time for mRNA production

358 and protein synthesis, so it is perhaps not surprising that it would not underlie tolerance in

359 our static heat shock assay (Sorensen et al., 2013). Moreover, rapid heating mimics the

360 acute stressors likely to be encountered by foraging workers, which tend to be older and

361 more resource-starved (Dussutour et al., 2016) and may be limited in their ability to

362 mount a robust response (Verbeke et al., 2001). Thus, lower-cost structural adaptations

363 that reduce susceptibility rather than enhanced damage repair may be selected for as the

364 primary mechanism of acute stress resistance in ground-foraging ants.

365 The heat shock response may be more important under slow-heating or extended

366 sub-lethal conditions, such as might be encountered over the course of an entire day or

367 during a longer period of high temperature (Overgaard et al., 2012; Sorensen et al.,

368 2013). In social insects such as ants, the subterranean nest may act as an effective buffer

369 to these types of temperature extremes, weakening selection on Hsp-mediated thermal 
370 limits. Both A. picea and A. rudis make their nests in rotting logs and underground, and

371 colonies regularly move their nests short distances in response to temperature and

372 humidity changes. Preliminary data suggest that CTmax measured with a slow-ramp

373 protocol $\left(0.1^{\circ} \mathrm{C} \mathrm{min}^{-1}\right)$ in fact does not vary across this set of species and populations (A.

374 Nguyen, unpublished data).

375 It is important to note that environment and phylogeny at least partially covary:

376 thermal variation is arrayed along a North-South axis, leading to greater geographic

377 distance and potential for genetic isolation between more thermally divergent

378 populations. Because A. picea occupies significantly cooler habitats than does A. rudis,

379 and the two clades of A. rudis correspond to geographically northern (and cooler) and

380 southern (warmer) regions, adaptive responses to temperature associated with these

381 historical shifts into novel thermal niches are more likely to be captured by their

382 corresponding phylogenetic axes than by Tmax. Although most of the Hsp expression

383 properties showed no phylogenetic signal, the basal level of $H s p 40$ varied significantly

384 along two of the three phylogenetic axes.

385 Interestingly, however, this effect was in the opposite direction than that expected

386 from environmental selection: the most southern clade of $A$. rudis, which experiences the

387 warmest temperatures, had significantly lower $H s p 40$ basal expression than the more

388 northern clades. This pattern of basal expression matches the results of a much more

389 phylogenetically distant comparison between warm- and cool-climate ants (Nguyen et al.

390 2016). Reduction in $H s p 40$ production in the southern $A$. rudis clade may be indicative

391 of a shift in investment to alternate, non-Hsp mediated mechanisms of resistance to

392 chronically extreme temperatures. Although evolutionary enhancement of the heat shock 
393 response in more thermally tolerant species has been documented in a number of systems,

394 the most common pattern associated with adaptation to higher temperatures is an upward

395 shift of the Hsp activation temperature, suggesting that in such species the enzymes that

396 Hsps protect are less susceptible to damage (Gehring and Wehner, 1995; Hofmann and

397 Somero, 1996; Mizrahi et al., 2012; Tomanek and Somero, 1999).

398 Similarly, some comparative studies have shown reduced, rather than enhanced,

399 Hsp activity associated with more extreme environments (Bedulina et al., 2013; Bedulina

400 et al., 2010; Hu et al., 2014; Narum et al., 2013). Production and maintenance of a

401 standing stock of Hsp proteins are likely to be costly, both because of direct effects of

402 cytoplasmic Hsp chaperones on cellular functions (Krebs and Feder, 1997, 1998b) and

403 because of energetic costs that reduce available resources (Krebs and Bettencourt, 1999;

404 Krebs and Feder, 1998a; Silbermann and Tatar, 2000; Sorensen et al., 1999). In

405 ectotherms such as ants, increasing temperature accelerates both growth rate and

406 metabolism, so the heat shock response is likely to become more costly at the same time

407 as it is triggered more frequently and thus may not be the most efficient resistance

408 mechanism under more extreme conditions (Stanton-Geddes et al., 2016).

409 In contrast to the limited evolved responses to climatic conditions, higher

410 acclimation temperature significantly increased both baseline expression and magnitude

411 of induction in two interacting Hsp genes: baseline levels of $H s c 70-4$ were elevated,

412 while induction increased in $H s p 40$. Although Hsp70 can interact directly with denatured

413 proteins, its intrinsic ATPase activity is low, and complex formation with targets is

414 substantially enhanced by Hsp40 (Fan et al., 2003; Laufen et al., 1999). Because these

415 two proteins directly interact, complementary modifications of their expression may 
416 improve the sensitivity and speed of response in acclimated individuals without overly

417 retarding normal metabolic processes. Heat shock proteins are produced relatively

418 rapidly in response to stressors, on the order of minutes (Lindquist, 1980), but producing

419 both proteins following exposure to a stressor may lead to a significantly slower response

420 than a strategy of having one member of the complex available to be recruited

421 immediately upon production of its partner. Hsp40 also may be activated at lower

422 temperatures than Hsp70 (Nguyen et al. 2016), so by making Hsp40 the limiting protein

423 in the pathway, the overall response can be triggered at lower temperatures in advance of

424 significant damage.

425 There is abundant evidence that the heat shock response responds dynamically to

426 environmental change over multiple time scales, in line with the predictions of the

427 Beneficial Acclimation Hypothesis for individual traits (Huey et al., 1999; Woods and

428 Harrison, 2002). Rapid, short-term exposure to a stressor leads to a hardening response,

429 in which protective upregulation of Hsp genes temporarily extends upper thermal limits

430 in the face of subsequent heat shocks (Krebs and Loeschcke, 1994). Chronic exposure to

431 sublethal temperatures also typically leads to enhanced Hsp activity, which can occur

432 seasonally (Dietz and Somero, 1992; Fader et al., 1994; Hamdoun et al., 2003; Hofmann

433 and Somero, 1996; Roberts et al., 1997) or in response to short-term rearing conditions

434 (Karl et al., 2008; Kristensen et al., 2016; Li et al., 2012; Lucentini et al., 2002).

435 Although neither of the temperatures to which colonies were exposed in this study were

436 likely to be directly stressful to adult workers (Nguyen et al. 2016), if nest and external

437 temperatures are correlated, workers leaving for foraging trips may benefit from using

438 even modestly elevated nest temperatures as a cue to anticipate stressful external 
439 conditions. Alternatively, worker responsiveness could be non-adaptive in adults but

440 carried over from mechanisms used in the larval stage, when individuals are relatively

441 immobile and can be faced with chronic thermal stress (Sambucetti et al., 2013).

442 Over the next 50-70 years, northeastern deciduous forest habitats are projected to

443 increase in mean annual temperatures by $4-8^{\circ} \mathrm{C}$ (Kunkel et al., 2013), pushing resident

444 species toward their physiological limits. The results of this study reveal a similar

445 capacity to plastically adjust the heat shock response to elevated temperatures across the

446 latitudinal range of both $A$. picea and A. rudis. This suggests that, at least in the short

447 term, they may possess some resiliency to the direct impacts of temperature increases

448 throughout their ranges. Reliance on the heat shock response, however, is likely to be

449 accompanied by increasing costs that will disproportionately affect cooler-climate

450 species; indeed, the elevational boundary between A. picea and A. rudis in the Smoky

451 Mountains is already moving upwards (Warren and Chick, 2013), while A. rudis is being

452 displaced in warmer areas by a more thermally tolerant species, Crematogaster lineolata

453 (Resasco et al., 2014). Understanding how stress-related costs affect growth rates and

454 competitive ability will be important for predicting their ability to persist in a changing

455 landscape.

458 Acknowledgements

459 We thank Joseph Karlik and Mary Vincent for assistance in collecting and rearing

460 colonies for the duration of this study, as well as Lacy Chick, Mike Herrmann, Jackie

461 Fitzgerald, Katie Miller, and Aaron Ellison for additional help collecting Aphaenogaster 
462 colonies. We also thank Janet Shurtleff and Carole Saravitz at the Phytotron facility at

463 NC State University. This work was supported by the National Science Foundation

464 [DEB-1136644].

465 All data, protocols and statistical analyses are publically available on Zenodo:

466 https://zenodo.org/record/164922\#.WCCPfvSrEud, doi:10.5281/zenodo.164922

References

Addo-Bediako, A., Chown, S.L., Gaston, K.J., 2000. Thermal tolerance, climatic variability and latitude. P Roy Soc B-Biol Sci 267, 739-745.

Anderson, A.R., Collinge, J.E., Hoffmann, A.A., Kellett, M., McKechnie, S.W., 2003. Thermal tolerance trade-offs associated with the right arm of chromosome 3 and marked by the hsr-omega gene in Drosophila melanogaster. Heredity 90, 195-202.

Barshis, D.J., Ladner, J.T., Oliver, T.A., Seneca, F.O., Traylor-Knowles, N., Palumbi, S.R., 2013. Genomic basis for coral resilience to climate change. P Natl Acad Sci USA 110, 1387-1392.

Bedulina, D.S., Evgen'ev, M.B., Timofeyev, M.A., Protopopova, M.V., Garbuz, D.G., Pavlichenko, V.V., Luckenbach, T., Shatilina, Z.M., Axenov-Gribanov, D.V., Gurkov, A.N., Sokolova, I.M., Zatsepina, O.G., 2013. Expression patterns and organization of the hsp70 genes correlate with thermotolerance in two congener endemic amphipod species (Eulimnogammarus cyaneus and E. verrucosus) from Lake Baikal. Mol Ecol 22, 1416-1430.

Bedulina, D.S., Zimmer, M., Timofeyev, M.A., 2010. Sub-littoral and supra-littoral amphipods respond differently to acute thermal stress. Comp Biochem Phys B 155, 413-418.

Bettencourt, B.R., Feder, M.E., 2001. Hsp70 duplication in the Drosophila melanogaster species group: How and when did two become five? Mol Biol Evol 18, 1272-1282.

Bhatkar, A., Whitcomb, W.H., 1970. Artificial diet for rearing various species of ants. Florida Entomologist 53, 229-232.

Blackburn, S., van Heerwaarden, B., Kellermann, V., Sgro, C.M., 2014. Evolutionary capacity of upper thermal limits: beyond single trait assessments. J Exp Biol 217, 1918-1924.

Cahill, A.E., Aiello-Lammens, M.E., Fisher-Reid, M.C., Hua, X., Karanewsky, C.J., Ryu, H.Y., Sbeglia, G.C., Spagnolo, F., Waldron, J.B., Wiens, J.J., 2014. Causes of warmedge range limits: systematic review, proximate factors and implications for climate change. J Biogeogr 41, 429-442.

Chandrakanth, N., Ponnuvel, K.M., Moorthy, S.M., Sasibhushan, S., Sivaprasad, V., 2015. Analysis of transcripts of heat shock protein genes in silkworm, Bombyx mori (Lepidoptera: Bombycidae). Eur J Entomol 112, 676-687.

DeMarco, B.B., Cognato, A.I., 2016. A multiple-gene phylogeny reveals polyphyly among eastern North American Aphaenogaster species. Zoologica Scripta. 
Dheda, K., Huggett, J.F., Bustin, S.A., Johnson, M.A., Rook, G., Zumla, A., 2004. Validation of housekeeping genes for normalizing RNA expression in real-time PCR. Biotechniques 37, 112-+.

Diamond, S.E., Sorger, D.M., Hulcr, J., Pelini, S.L., Del Toro, I., Hirsch, C., Oberg, E., Dunn, R.R., 2012. Who likes it hot? A global analysis of the climatic, ecological, and evolutionary determinants of warming tolerance in ants. Global Change Biol 18, 448456.

Diamond, S.E., Nichols, L.M., Pelini, S.L., Penick, C.A., Barber, G.W., Cahan, S.H., Dunn, R.R., Ellison, A.M., Sanders, N.J. and Gotelli, N.J., 2016. Climatic warming destabilizes forest ant communities. Science Advances 2:e1600842.

Dietz, T.J., Somero, G.N., 1992. The threshold induction temperature of the 90-Kda heatshock protein is subject to acclimatization in eurythermal Goby fishes (Genus Gillichthys). P Natl Acad Sci USA 89, 3389-3393.

Diniz, J.A.F., De Sant'ana, C.E.R., Bini, L.M., 1998. An eigenvector method for estimating phylogenetic inertia. Evolution 52, 1247-1262.

Dong, Y.W., Williams, G.A., 2011. Variations in cardiac performance and heat shock protein expression to thermal stress in two differently zoned limpets on a tropical rocky shore. Mar Biol 158, 1223-1231.

Dussutour, A., Poissonnier, L.A., Buhl, J., Simpson, S.J., 2016. Resistance to nutritional stress in ants: when being fat is advantageous. J Exp Biol 219, 824-833.

Fader, S.C., Yu, Z.M., Spotila, J.R., 1994. Seasonal-variation in heats-shock proteins (Hsp70) in stream fish under natural conditions. J Therm Biol 19, 335-341.

Fan, C.Y., Lee, S., Cyr, D.M., 2003. Mechanisms for regulation of Hsp70 function by Hsp40. Cell Stress Chaperon 8, 309-316.

Feder, M.E., Hofmann, G.E., 1999. Heat-shock proteins, molecular chaperones, and the stress response: Evolutionary and ecological physiology. Annu Rev Physiol 61, 243282.

Fitzgerald-Dehoog, L., Browning, J., Allen, B.J., 2012. Food and heat stress in the California mussel: Evidence for an energetic trade-off between survival and growth. Biol Bull-Us 223, 205-216.

Gehring, W.J., Wehner, R., 1995. Heat-shock protein-synthesis and thermotolerance in Cataglyphis, an ant from the Sahara Desert. P Natl Acad Sci USA 92, 2994-2998.

Haguenauer, A., Zuberer, F., Ledoux, J.B., Aurelle, D., 2013. Adaptive abilities of the Mediterranean red coral Corallium rubrum in a heterogeneous and changing environment: from population to functional genetics. J Exp Mar Biol Ecol 449, 349357.

Hamdoun, A.M., Cheney, D.P., Cherr, G.N., 2003. Phenotypic plasticity of HSP70 and HSP70 gene expression in the Pacific oyster (Crassostrea gigas): Implications for thermal limits and induction of thermal tolerance. Biol Bull-Us 205, 160-169.

Hoekstra, L.A., Montooth, K.L., 2013. Inducing extra copies of the Hsp70 gene in Drosophila melanogaster increases energetic demand. Bmc Evol Biol 13.

Hofmann, G.E., Somero, G.N., 1996. Interspecific variation in thermal denaturation of proteins in the congeneric mussels Mytilus trossulus and M. galloprovincialis: Evidence from the heat shock response and protein ubiquitination. Mar Biol 126, 6575 . 
Hu, J.T., Chen, B., Li, Z.H., 2014. Thermal plasticity is related to the hardening response of heat shock protein expression in two Bactrocera fruit flies. J Insect Physiol 67, 105-113.

Huey, R.B., Berrigan, D., Gilchrist, G.W., Herron, J.C., 1999. Testing the adaptive significance of acclimation: A strong inference approach. Am Zool 39, 323-336.

Karl, I., Janowitz, S.A., Fischer, K., 2008. Altitudinal life-history variation and thermal adaptation in the copper butterfly Lycaena tityrus. Oikos 117, 778-788.

Koenigstein, S., Pohlmann, K., Held, C., Abele, D., 2013. Ecological comparison of cellular stress responses among populations - normalizing RT-qPCR values to investigate differential environmental adaptations. Bmc Ecol 13.

Krebs, R.A., Bettencourt, B.R., 1999. Evolution of thermotolerance and variation in the heat shock protein, Hsp70. Am Zool 39, 910-919.

Krebs, R.A., Feder, M.E., 1997. Deleterious consequences of Hsp7O overexpression in Drosophila melanogaster larvae. Cell Stress Chaperon 2, 60-71.

Krebs, R.A., Feder, M.E., 1998a. Experimental manipulation of the cost of thermal acclimation in Drosophila melanogaster. Biol J Linn Soc 63, 593-601.

Krebs, R.A., Feder, M.E., 1998b. Hsp70 and larval thermotolerance in Drosophila melanogaster: how much is enough and when is more too much? J Insect Physiol 44, 1091-1101.

Krebs, R.A., Loeschcke, V., 1994. Effects of exposure to short-term heat-stress on fitness components in Drosophila melanogaster. J Evolution Biol 7, 39-49.

Kristensen, T.N., Kjeldal, H., Schou, M.F., Nielsen, J.L., 2016. Proteomic data reveal a physiological basis for costs and benefits associated with thermal acclimation. J Exp Biol 219, 969-976.

Kunkel, K.E., Stevens, L.E., Stevens, S.E., Sun, L., Janssen, E., Wuebbles, D., Rennells, J., DeGaetano, A., Dobson, J.G., 2013. Regional climate trends and scenarios for the U.S. National Climate Assessment Part I: Climate of the Northeast U.S. NOAA Technical Report NESDIS.

Laufen, T., Mayer, M.P., Beisel, C., Klostermeier, D., Mogk, A., Reinstein, J., Bukau, B., 1999. Mechanism of regulation of Hsp70 chaperones by DnaJ cochaperones. P Natl Acad Sci USA 96, 5452-5457.

Li, J.Q., He, Q.G., Sun, H., Liu, X., 2012. Acclimation-dependent expression of heat shock protein 70 in Pacific abalone (Haliotis discus hannai Ino) and its acute response to thermal exposure. Chin J Oceanol Limn 30, 146-151.

Li, Q.R., Xiao, Y., Wu, F.Q., Ye, M.Q., Luo, G.Q., Xing, D.X., Li, L., Yang, Q., 2014. Analysis of midgut gene expression profiles from different silkworm varieties after exposure to high temperature. Gene 549, 85-96.

Lindquist, S., 1980. Translational efficiency of heat-induced messages in Drosophila melanogaster cells. J Mol Biol 137, 151-158.

Lindquist, S., 1986. The heat-shock response. Annu Rev Biochem 55, 1151-1191.

Livak, K.J., Schmittgen, T.D., 2001. Analysis of relative gene expression data using realtime quantitative PCR and the 2(T)(-Delta Delta C) method. Methods 25, 402-408.

Lubertazzi, D., 2012. The biology and natural history of Aphaenogaster rudis. Psyche Article ID 752815. 
592

593

594

595

596

597

598

599

600

601

602

603

604

605

606

607

608

609

610

611

612

613

614

615

616

617

618

619

620

621

622

623

624

625

626

627

628

629

630

631

632

633

634

635

636

Lucentini, L., Lorenzoni, M., Panara, F., Mearelli, M., 2002. Effects of short- and longterm thermal stress in perch (Perca fluviatilis) determined through fluctuating asymmetry and HSP70 expression. Ital J Zool 69, 13-17.

Martinez, B., Arenas, F., Trilla, A., Viejo, R.M., Carreno, F., 2015. Combining physiological threshold knowledge to species distribution models is key to improving forecasts of the future niche for macroalgae. Global Change Biol 21, 1422-1433.

Mizrahi, T., Goldenberg, S., Heller, J., Arad, Z., 2015. Natural variation in resistance to desiccation and heat shock protein expression in the land snail Theba pisana along a climatic gradient. Physiol Biochem Zool 88, 66-80.

Mizrahi, T., Goldenberg, S., Heller, J., Arad, Z., 2016. Geographic variation in thermal tolerance and strategies of heat shock protein expression in the land snail Theba pisana in relation to genetic structure. Cell Stress Chaperon 21, 219-238.

Mizrahi, T., Heller, J., Goldenberg, S., Arad, Z., 2012. The heat shock response in congeneric land snails (Sphincterochila) from different habitats. Cell Stress Chaperon 17, 639-645.

Narum, S.R., Campbell, N.R., Meyer, K.A., Miller, M.R., Hardy, R.W., 2013. Thermal adaptation and acclimation of ectotherms from differing aquatic climates. Mol Ecol 22, 3090-3097.

Nguyen, A.D., Gotelli, N.J., Cahan, S.H., 2016. The evolution of heat shock protein sequences, cis-regulatory elements, and expression profiles in the eusocial Hymenoptera. Bmc Evol Biol 16.

Overgaard, J., Kristensen, T.N., Sorensen, J.G., 2012. Validity of thermal ramping assays used to assess thermal tolerance in Arthropods. Plos One 7.

Palumbi, S.R., Barshis, D.J., Traylor-Knowles, N., Bay, R.A., 2014. Mechanisms of reef coral resistance to future climate change. Science 344, 895-898.

Paradis, E., Claude, J., Strimmer, K., 2004. APE: Analyses of Phylogenetics and Evolution in R language. Bioinformatics 20, 289-290.

Parsell, D.A., Lindquist, S., 1993. The function of heat-shock proteins in stress tolerance - degradation and reactivation of damaged proteins. Annu Rev Genet 27, 437-496.

Pelini, S.L., Diamond, S.E., Nichols, L.M., Stuble, K.L., Ellison, A.M., Sanders, N.J., Dunn, R.R., Gotelli, N.J., 2014. Geographic differences in effects of experimental warming on ant species diversity and community composition. Ecosphere 5.

Recknagel, H., Elmer, K.R., Meyer, A., 2013. A hybrid genetic linkage map of two ecologically and morphologically divergent Midas cichlid fishes (Amphilophus spp.) obtained by massively parallel DNA sequencing (ddRADSeq). G3-Genes Genom Genet 3, 65-74.

Resasco, J., Pelini, S.L., Stuble, K.L., Sanders, N.J., Dunn, R.R., Diamond, S.E., Ellison, A.M., Gotelli, N.J., Levey, D.J., 2014. Using historical and experimental data to reveal warming effects on ant assemblages. Plos One 9.

Roberts, D.A., Hofmann, G.E., Somero, G.N., 1997. Heat-shock protein expression in Mytilus californianus: Acclimatization (seasonal and tidal-height comparisons) and acclimation effects. Biol Bull-Us 192, 309-320.

Rodriguez-Verdugo, A., Carrillo-Cisneros, D., Gonzalez-Gonzalez, A., Gaut, B.S., Bennett, A.F., 2014. Different tradeoffs result from alternate genetic adaptations to a common environment. P Natl Acad Sci USA 111, 12121-12126. 
Rojo, C., Martinez-Ruiz, C., Carraminana, M., Rodrigo, M.A., 2015. Foreseeable global warming will differentially affect Chara vulgaris populations from different altitudes. Aquat Bot 122, 20-26.

Sambucetti, P., Scannapieco, A.C., Loeschcke, V., Norry, F.M., 2013. Heat-stress survival in the pre-adult stage of the life cycle in an intercontinental set of recombinant inbred lines of Drosophila melanogaster. J Exp Biol 216, 2953-2959.

Sawall, Y., Al-Sofyani, A., Hohn, S., Banguera-Hinestroza, E., Voolstra, C.R., Wahl, M., 2015. Extensive phenotypic plasticity of a Red Sea coral over a strong latitudinal temperature gradient suggests limited acclimatization potential to warming. Sci RepUk 5.

Schoville, S.D., Barreto, F.S., Moy, G.W., Wolff, A., Burton, R.S., 2012. Investigating the molecular basis of local adaptation to thermal stress: population differences in gene expression across the transcriptome of the copepod Tigriopus californicus. Bmc Evol Biol 12.

Shatilina, Z.M., Riss, H.W., Protopopova, M.V., Trippe, M., Meyer, E.I., Pavlichenko, V.V., Bedulina, D.S., Axenov-Gribanov, D.V., Timofeyev, M.A., 2011. The role of the heat shock proteins (HSP70 and sHSP) in the thermotolerance of freshwater amphipods from contrasting habitats. J Therm Biol 36, 142-149.

Sheth, S.N., Angert, A.L., 2014. The evolution of environmental tolerance and range size: A comparison of geographically restricted and widespread Mimulus. Evolution 68, 2917-2931.

Silbermann, R., Tatar, M., 2000. Reproductive costs of heat shock protein in transgenic Drosophila melanogaster. Evolution 54, 2038-2045.

Sorensen, J.G., Loeschcke, V., Kristensen, T.N., 2013. Cellular damage as induced by high temperature is dependent on rate of temperature change - investigating consequences of ramping rates on molecular and organismal phenotypes in Drosophila melanogaster. J Exp Biol 216, 809-814.

Sorensen, J.G., Michalak, P., Justesen, J., Loeschcke, V., 1999. Expression of the heatshock protein HSP70 in Drosophila buzzatii lines selected for thermal resistance. Hereditas 131, 155-164.

Stamatakis, A., 2014. RAxML version 8: a tool for phylogenetic analysis and postanalysis of large phylogenies. Bioinformatics 30, 1312-1313.

Stanton-Geddes, J., Nguyen, A., Chick, L., Vincent, J., Vangala, M., Dunn, R.R., Ellison, A.M., Sanders, N.J., Gotelli, N.J., Cahan, S.H., 2016. Thermal reactionomes reveal divergent responses to thermal extremes in warm and cool-climate ant species. Bmc Genomics 17.

Sunday, J.M., Bates, A.E., Dulvy, N.K., 2012. Thermal tolerance and the global redistribution of animals. Nat Clim Change 2, 686-690.

Tedeschi, J.N., Kennington, W.J., Tomkins, J.L., Berry, O., Whiting, S., Meekan, M.G., Mitchell, N.J., 2016. Heritable variation in heat shock gene expression: a potential mechanism for adaptation to thermal stress in embryos of sea turtles. P Roy Soc BBiol Sci 283.

Terblanche, J.S., Hoffmann, A.A., Mitchell, K.A., Rako, L., le Roux, P.C., Chown, S.L., 2011. Ecologically relevant measures of tolerance to potentially lethal temperatures. J Exp Biol 214, 3713-3725. 
682

683

684

685

686

687

688

689

690

691

692

693

694

695

696

697

698

699

700

701

702

703

704

705

706

707

Tomanek, L., Somero, G.N., 1999. Evolutionary and acclimation-induced variation in the heat-shock responses of congeneric marine snails (genus Tegula) from different thermal habitats: Implications for limits of thermotolerance and biogeography. J Exp Biol 202, 2925-2936.

Verbeke, P., Fonager, J., Clark, B.F.C., Rattan, S.I.S., 2001. Heat shock response and ageing: Mechanisms and applications. Cell Biol Int 25, 845-857.

Warren, R.J., Chick, L., 2013. Upward ant distribution shift corresponds with minimum, not maximum, temperature tolerance. Global Change Biol 19, 2082-2088.

White, M.G., Luca, L.E., Nonner, D., Saleh, O., Hu, B., Barrett, E.F., Barrett, J.N., 2007. Cellular mechanisms of neuronal damage from hyperthermia. Prog Brain Res 162, 347-371.

Woods, H.A., Harrison, J.F., 2002. Interpreting rejections of the beneficial acclimation hypothesis: When is physiological plasticity adaptive? Evolution 56, 1863-1866.

Yu, H., Wan, F.H., Guo, J.Y., 2012. Different thermal tolerance and hsp gene expression in invasive and indigenous sibling species of Bemisia tabaci. Biol Invasions 14, 15871595.

Tables

Table 1. Primers used for qPCR.

\begin{tabular}{|c|c|c|c|}
\hline Gene & Direction & 5'-3' sequence & $\begin{array}{c}\text { Amplicon Length } \\
\text { (bps) }\end{array}$ \\
\hline \multirow[t]{2}{*}{ Hsp83 } & Forward & AATTCGATGGAAARCAGYTGG & \\
\hline & Reverse & AAYTTGGCYTTGTCYTCCTC & 99 \\
\hline \multirow[t]{2}{*}{$H s c 70-4$} & Forward & GCGATYGARAAATCTACVGGC & \\
\hline & Reverse & TGYTCRTCYTCCGATCGGTA & 124 \\
\hline \multirow[t]{2}{*}{ Hsp4O } & Forward & AAAGATCGYGCYCARGATCC & \\
\hline & Reverse & GCYCGTCTRCATATYTTCATC & 100 \\
\hline \multirow[t]{2}{*}{$18 s$ rRNA } & Forward & СTCTTTCTTGATTCGGTGGGTG & \\
\hline & Reverse & TTAGCAGGCTAGAGTCTCGTTC & 100 \\
\hline
\end{tabular}


708 Table 2. Summary table of significant predictors from linear regression models for 709 relative basal expression ( $\triangle \Delta \mathrm{CT}$ relative to grand mean) and fold-induction in response to 710 heat shock $\left(\Delta \Delta \mathrm{CT}\right.$ relative to $\left.25^{\circ} \mathrm{C}\right)$ of Hsp83, Hsc70-4, and Hsp40. Significance level is 711 reported only for those factors included in the final model after forward AIC model 712 selection. Axes 1,2 and 3 represent the first three axes of phylogenetic variation from 713 PCoA decomposition (see Fig. 1 for nodes captured by each axis).

714

\begin{tabular}{|c|c|c|c|c|c|c|}
\hline \multirow[b]{2}{*}{ Gene } & \multirow[b]{2}{*}{$\begin{array}{c}\text { Expression } \\
\text { Type }\end{array}$} & \multicolumn{4}{|c|}{ Predictor } & \multirow[b]{2}{*}{$\begin{array}{c}\text { Axis } \\
3 \\
\end{array}$} \\
\hline & & $\begin{array}{c}\text { Rearing } \\
\text { Temperature }\end{array}$ & Tmax & Axis 1 & Axis 2 & \\
\hline \multirow[t]{2}{*}{ Hsp83 } & Basal & & & ns & & ns \\
\hline & Induction & + & & & & \\
\hline \multirow[t]{2}{*}{ Hsc70-4 } & Basal & ++ & & & & \\
\hline & Induction & ns & & & & \\
\hline \multirow[t]{2}{*}{ Hsp40 } & Basal & $\mathrm{ns}$ & & ns & + & +++ \\
\hline & Induction & + & & & ns & \\
\hline
\end{tabular}

715 ns $=$ not significant, ${ }^{+} \mathrm{p}<0.05,{ }^{++} \mathrm{p}<0.01,{ }^{+++} \mathrm{p}<0.001$. 
723 Figure 1.Map of collection sites of Aphaenogaster picea and A. rudis, with the topology recovered from a ddRADseq-based Kimura 2-parameter NJ reconstruction of genetic relationships among colonies. Only bootstrap values of 100 are shown. Color codes of field sites correspond to clade membership of colonies collected at the site: A. picea (blue circles), $A$. rudis (northern clade $=$ light orange triangles, southern clade $=$ dark orange squares), and a basal clade with intermediate morphological characters (gray diamonds). Dark gray shaded ovals indicate the nodes captured by the first three principal coordinate axes of genetic variation.

Figure 2. Relationship between maximal annual temperature of the site of field collection and basal expression relative to the grand mean $(\Delta \Delta \mathrm{CT})$ or fold induction in response to one hour of heat shock at $37^{\circ} \mathrm{C}$ for Hsp83 (A,B), Hsc70-4 (C,D) and Hsp40 (E,F). Points were fitted with spline curves with $95 \%$ confidence intervals indicated by the red line and shading, respectively.

Figure 3. Box plot of relative Hsp40 basal expression $(\Delta \Delta \mathrm{CT})$ across the four clades differentiated by PCA analysis; axes 2 and 3 were significant in the full model. Letters indicate significantly different groupings as indicated by Tukey's post-hoc pairwise comparisons.

Figure 4. Effect of rearing temperature on relative basal expression and induction in response to heat shock for $H s p 83$ (A,B), $H s c 70-4 h 2$ (C,D) and $H s p 40$ (E,F). P-values indicate the level of significance of rearing temperature from regression analysis.

751

Fig. S1 PCoA scatterplots of the first three axes of variation in the Aphaenogaster SNP-based genetic distance matrix. A) Axis 1 versus axis 2, which differentiate the A. picea-A. rudis (axis 1) and intermediate basal clade (axis 2) clusters. B) Axis 2 versus axis 3 , which differentiates the southern and northern clades of $A$. rudis. 

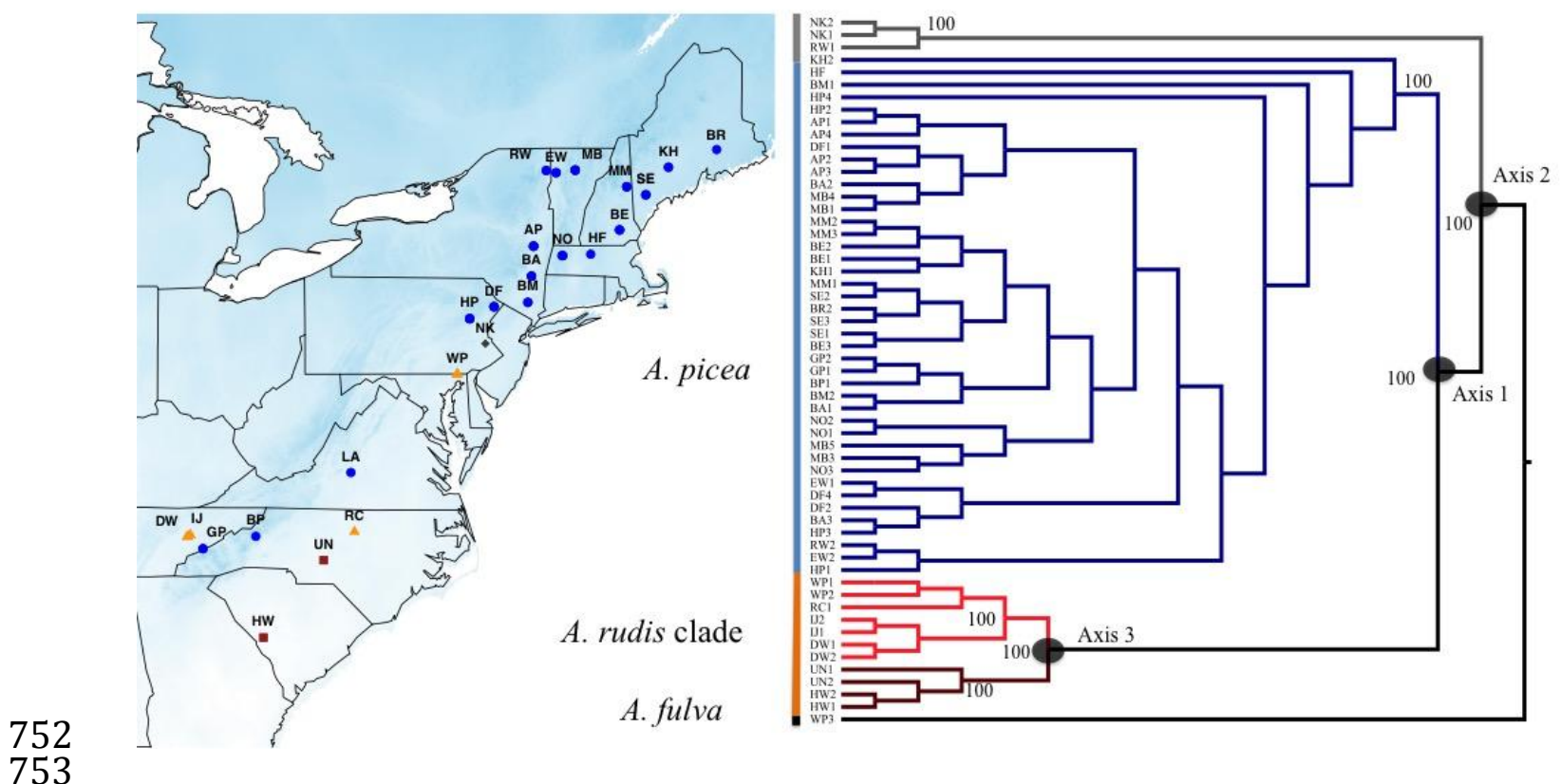

753 

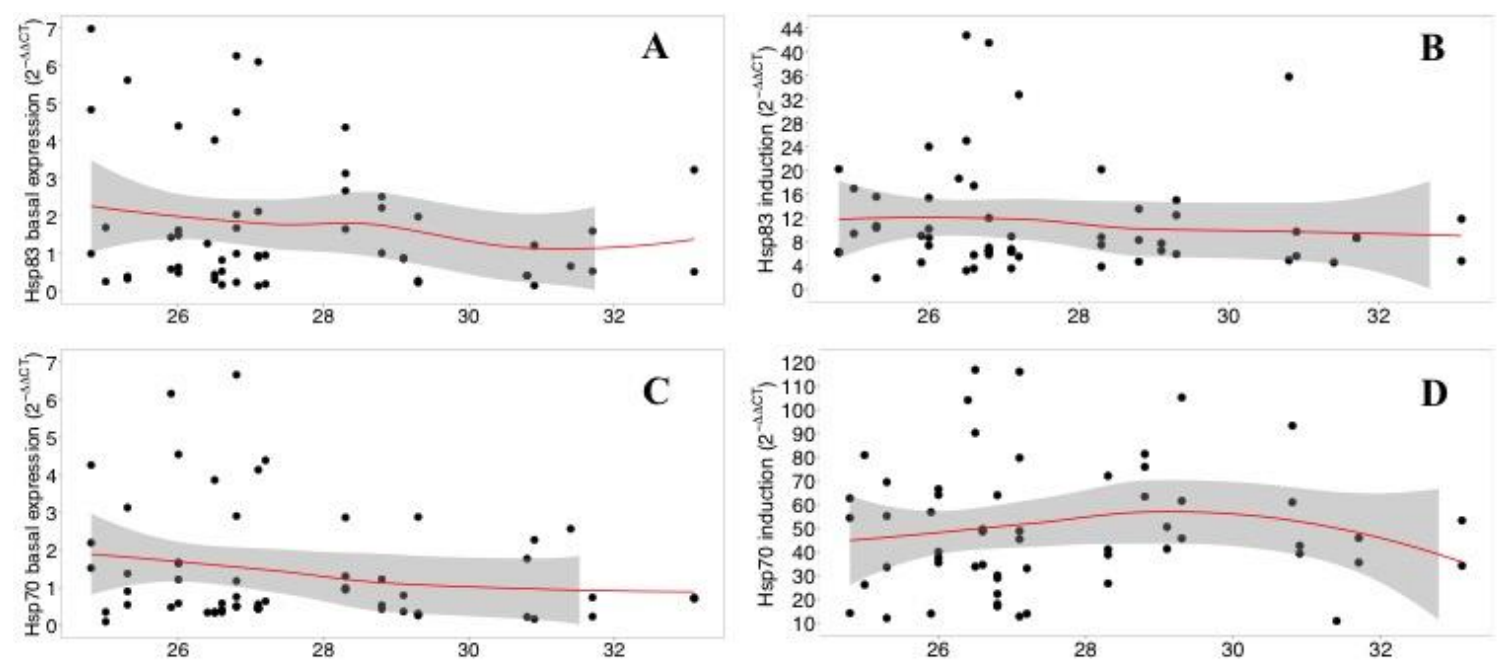

754
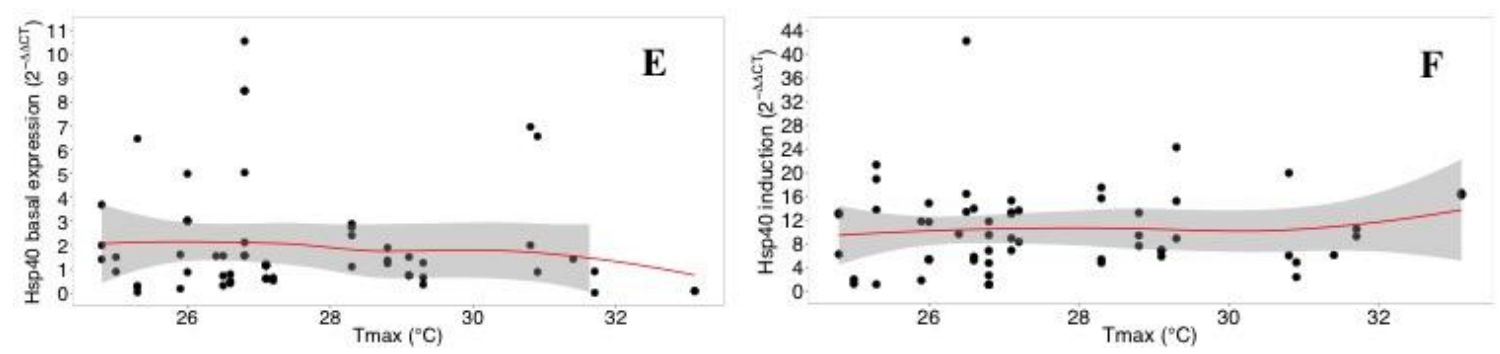

755 


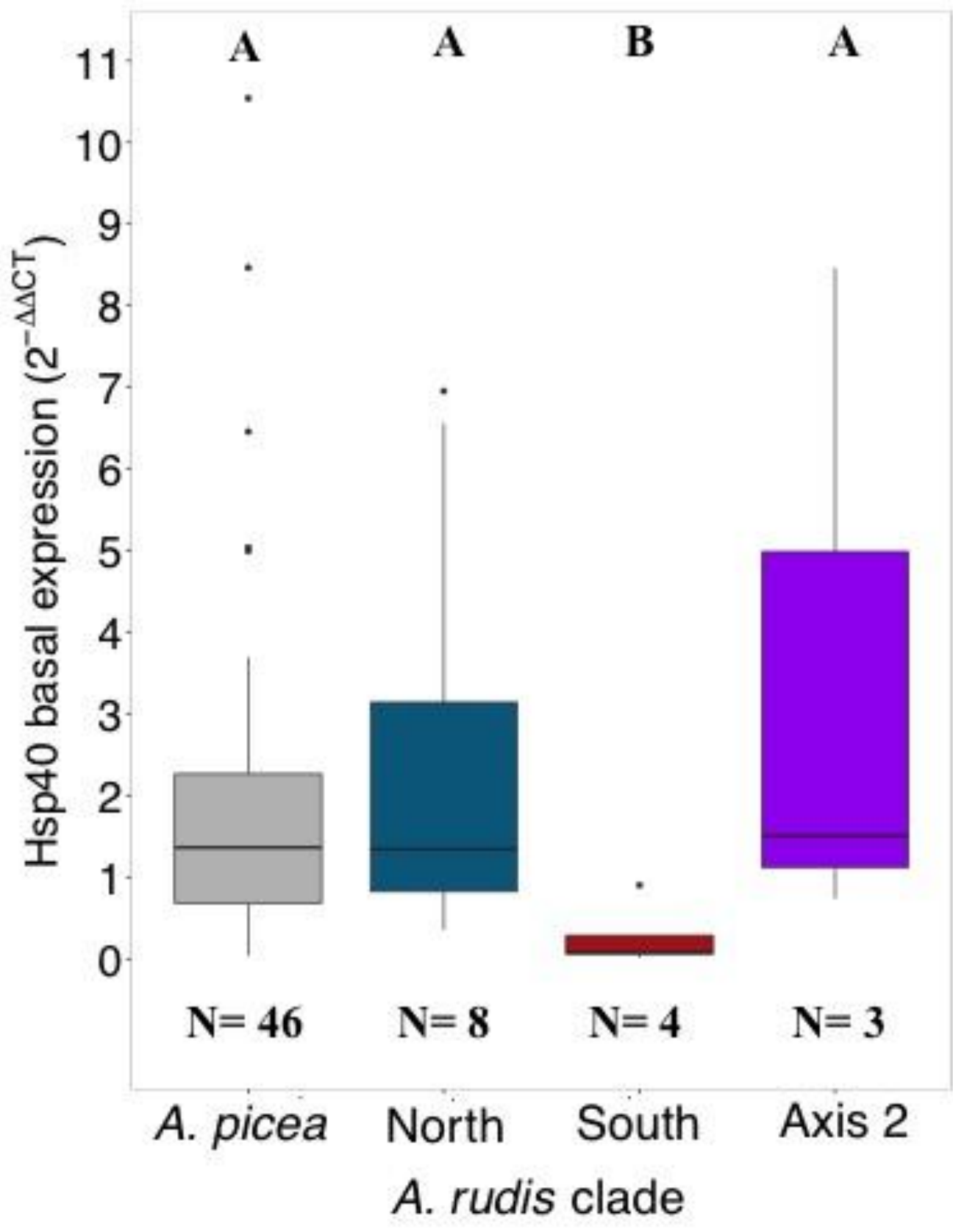

756

757 

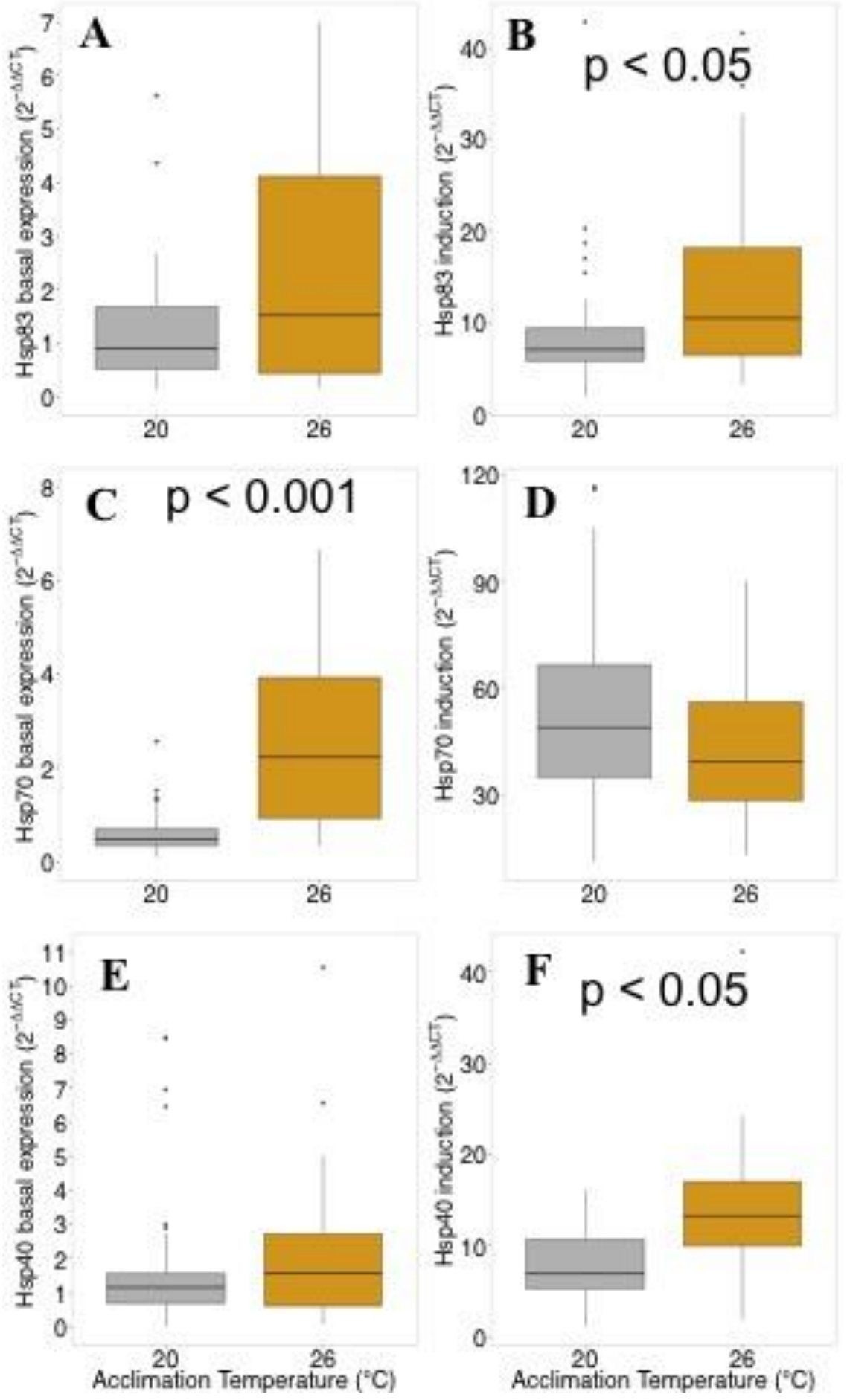